\title{
Simulation of Permanent Magnet Synchronous Motor Vector Control \\ System Based on Simplorer \& Maxwell
}

\author{
Guanyue Zhang ${ }^{1,}$, Kuangcheng $\mathrm{Li}^{1, \mathrm{~b}}$ and ${ }^{*}$ Chunguang $\mathrm{Liu}^{1, \mathrm{c}}$ \\ ${ }^{1}$ Academy of Armored Force Beijing China \\ anottinghilllove@163.com, b likuangcheng@163.com, cliu_mu2000@163.com \\ *stand for corresponding author
}

\section{Keywords: Synchronous Maxwell Simplorer Vector control}

Abstract:In this paper, the electromagnetic model of Permanent magnet synchronous motor (PMSM) is established by using the RMxprt module self-brought by Maxwell, and the two-dimensional model is generated to conduct the electromagnetic simulation analysis. By using Simplorer as the simulation platform for driving circuit, controller and position detection parts of Permanent magnet synchronous motor, a joint simulation model of PMSM vector control with Maxwell and Simplorer is built through Simplorer communication interface, the correctness and rationality of the motor control scheme and simulation method are verified.

\section{Introduction}

Electric drive is a kind of transmission system which converts electrical energy into mechanical energy and uses electrical energy to drive load. Among them, the PMSM vector control system, as a part of the electric drive, has the characteristics of high power density, energy saving, high efficiency and accurate speed adjustment, and is widely used in various fields. At present, the simulation of PMSM vector control system is mostly modeled by Matlab software. The motor model in Matlab software is an ideal model, the simulation precision is not high enough to build a more efficient and accurate simulation model for the electric drive system [1]. Therefore, this paper uses Maxwell and Simplorer respectively to establish the model and the joint simulation of the permanent magnet synchronous motor body and the motor drive control system. Among them, Maxwell is mainly used for electromagnetic simulation analysis of motor, transformer, actuator and so on; The electromagnetic model of motor is established by using the RMxprt module self-brought by Maxwell directly input motor parameters, and then the two-dimensional model of motor is generated. Simplorer is a simulation and analysis software used in many fields, which is mainly used in the design and modeling of electric and electromagnetism, and has powerful system simulation function, which can realize the joint design and simulation analysis of power electronics, sensors, motors and control systems conveniently. Compared with the single Matlab simulation, Maxwell and Simplorer collaborative simulation makes the system simulation results more accurate and reliable.

\section{Vector Control System Structure}

The control system structure diagram as shown in Fig. 1 which shows that the vector control system mainly includes: the rotation-loop and the current loop PI control module, the coordinate transform module, the SVPWM algorithm module and the inverter module[2]. 
From the control principle, vector control is the stator current decomposition of permanent magnet synchronous motor, two orthogonal decoupling torque current and excitation current are obtained, torque current is mainly used to generate electromagnetic torque, adjusting excitation current can change the air gap synthetic magnetic field in straight axis direction, and can increase the speed range under the condition of constant motor power[3].

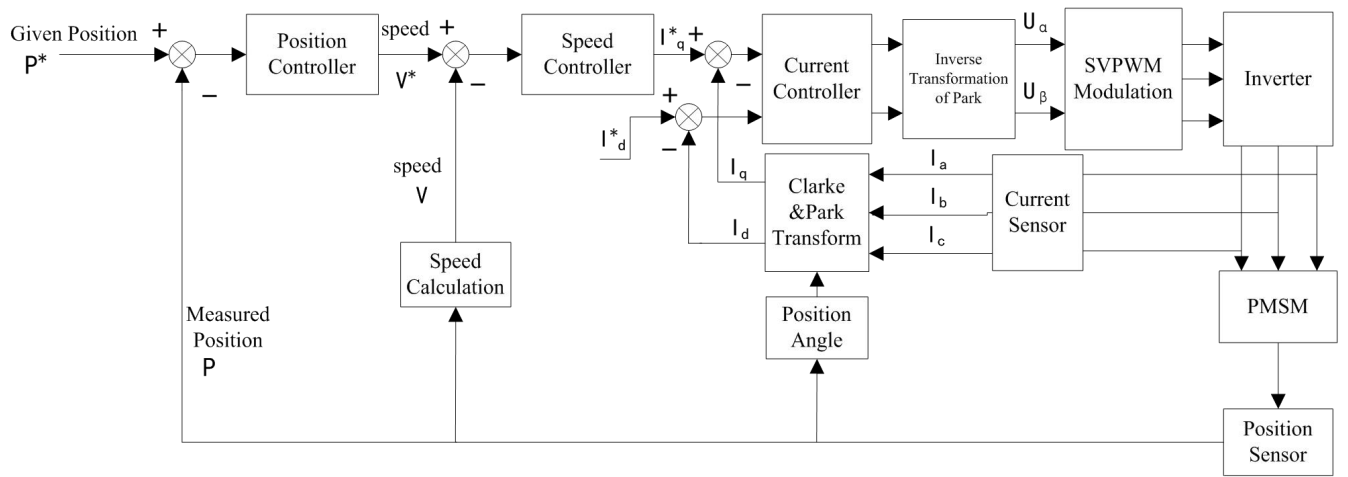

Fig. 1. Structure of vector control system

\section{Establishment of the Finite Element Model of IPM Motor}

Using the RMxprt module in Maxwell, input motor stator diameter, iron core length, groove shape, permanent magnet size and other parts' size, generate motor model, then add material attributes to generate Maxwell 2D model, set motor's moving parts, boundary conditions and split the motor. The basic structural parameters of permanent magnet synchronous motor are shown in Table 1. In order to obtain the accurate electromagnetic analysis result of the motor, define the boundary condition, set the excitation source, and make the network partition of the motor components. The two-dimensional model and its network dissection of motor body Maxwell are shown in Fig. 2, which shows that the establishment of the motor model is ideal and conforms to the system requirements.

Table 1. Basic Structural Parameters of Permanent Magnet Synchronous Motor

\begin{tabular}{llll}
\hline Parameter & Value & Parameter & Value \\
Power Rating /kw & 10 & Number of Stator Slots & 12 \\
Rated Voltage /V & 196 & Number of Pole Pairs & 4 \\
Rated Torque /N.m & 31 & Number of Phases & 3 \\
Rated Speed /(r/min) & 3000 & Iron Core Length /Mm & 92 \\
Stator Internal Diameter $/ \mathrm{mm}$ & 180 & Parallel Branch Number & 4 \\
Stator External Diameter $/ \mathrm{mm}$ & 111.5 & & \\
\hline
\end{tabular}

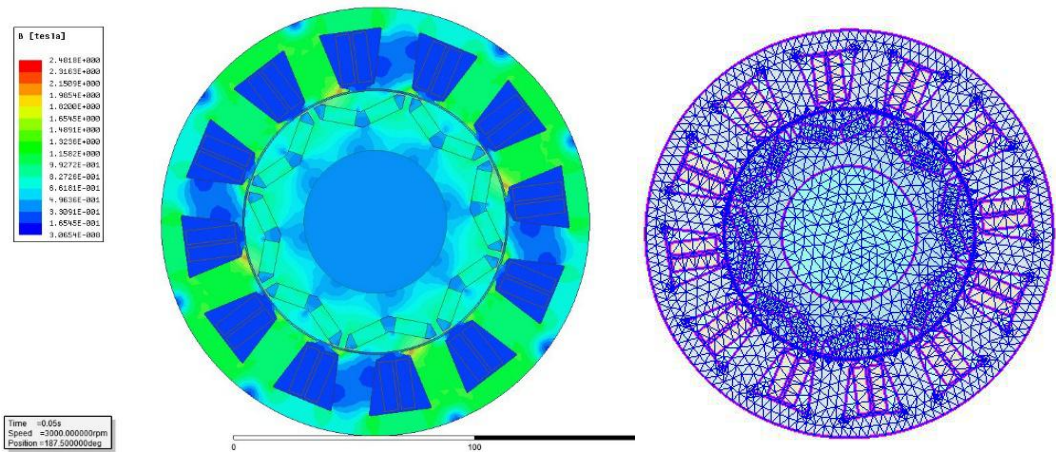

Fig. 2Two dimensional model of IPM motor and its network dissection 


\section{Simplorer Modeling of Control System}

\section{The Rotation-loop and the Current Loop PI Control Module}

In the Simplorer, thd the integral adjuster are used to feedback the speed signal and the current signal of the motor, which can achieve the floating control to the speed and torque[4]. The U_BETA and U_ALPHA output by this module is the input signal of SVPWM.

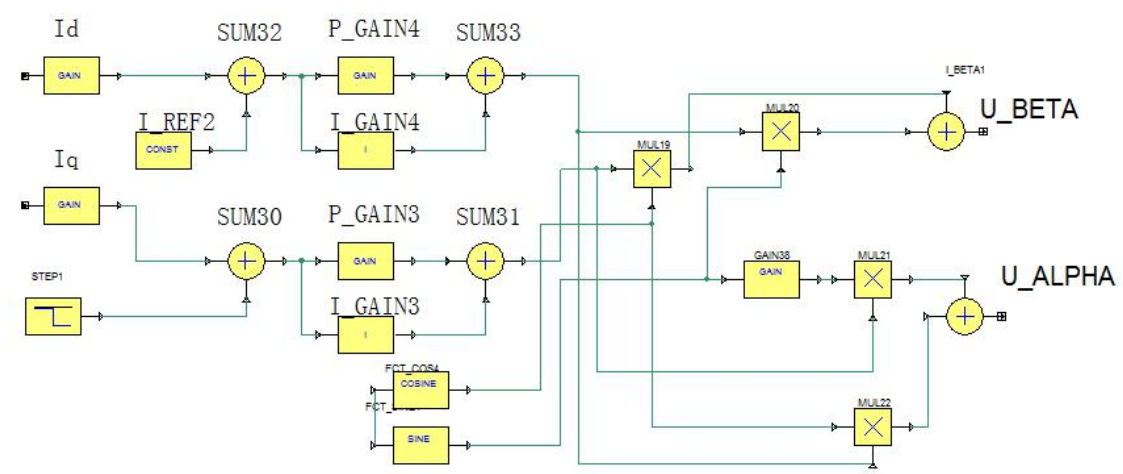

Fig. 3. The closed loop PI controller

\section{Coordinate Transform Module}

The module includes Clark transform and Park transform, through Clark transform, transforms the three-phase static ABC coordinate system into two-phase static $\alpha-\beta$ coordinate system; Then through the Park transform, transforms the two-phase static $\alpha-\beta$ coordinate system into two-phase rotating d-q coordinate system, and converts the three-phase current of the current transducer to the direct current in the $\mathrm{d}-\mathrm{q}$ coordinate system as the input of PI regulator[5]. The Clark Transform and the Park transform module are shown in Fig. 4.

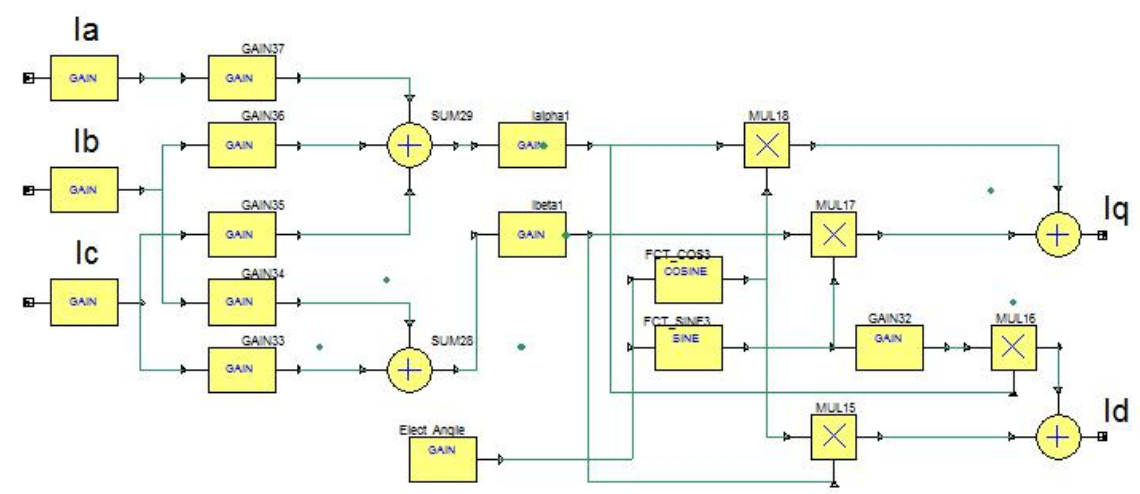

Fig. 4. Clark transform and Park transform module

\section{SVPWM Algorithm Module}

The module is a key module in the control algorithm, which mainly includes the sector judgment sub-module, the basic voltage function time calculation sub-module, the switching time calculation sub-module, and the triggering pulse generating sub-module[6]. 


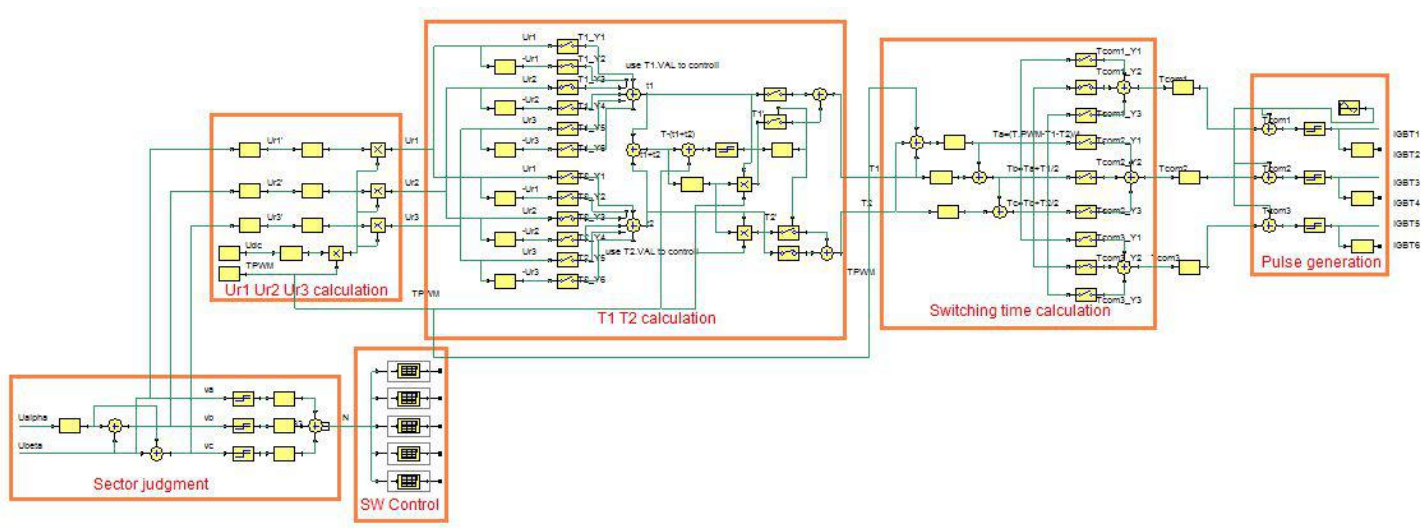

Fig. 5. SVPWM algorithm module

\section{Inverter and Permanent Magnet Synchronous Motor Module}

Fig. 6 is the main circuit module, the inverter mainly consists of 6 IGBT and 6 diodes, the power supply is the DC voltage source. Through SVPWM control module to generate the control signal and drive the conduction and turn-off of IGBT.

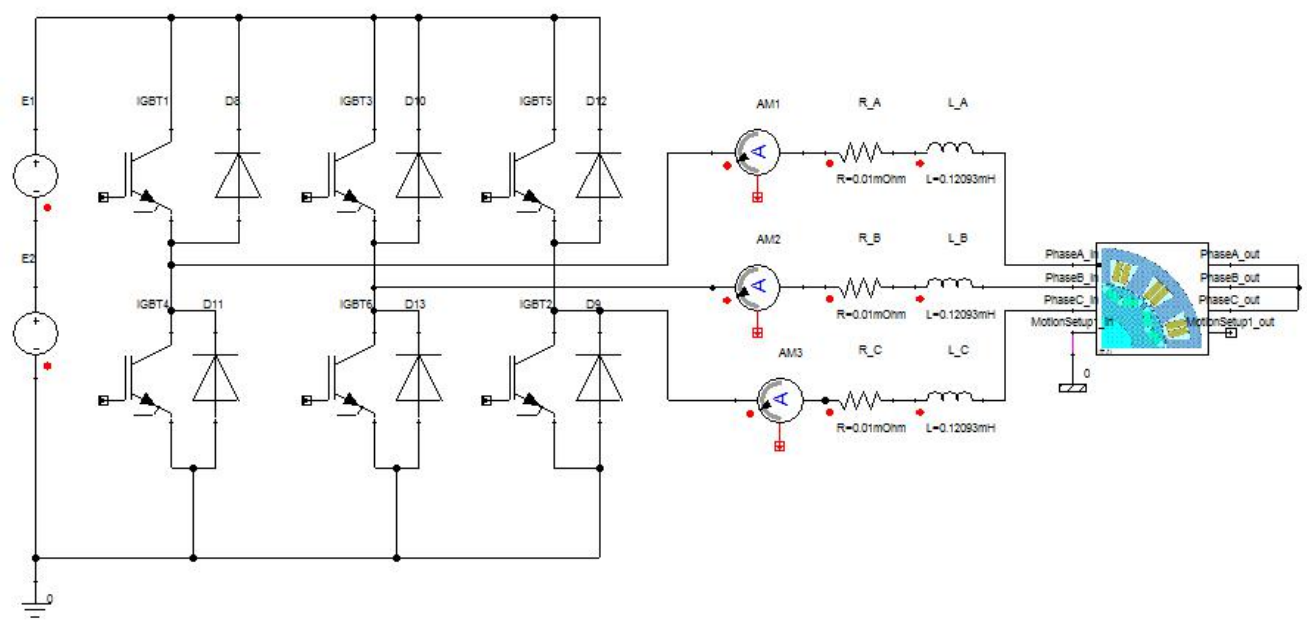

Fig. 6. Inverter and permanent magnet synchronous motor module

\section{Simulation and Result Analysis}

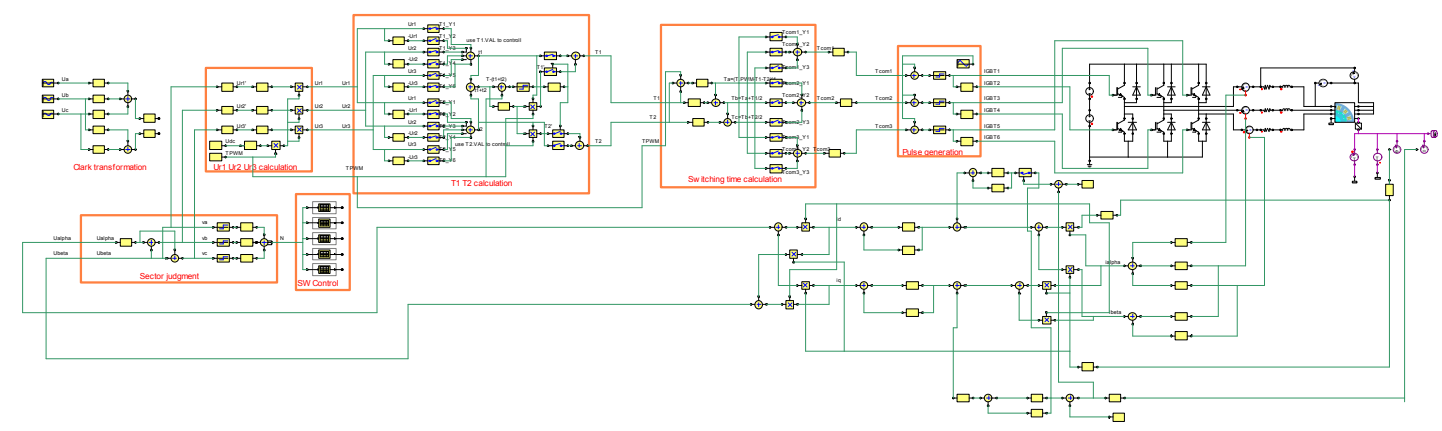

Fig. 7. Vector control system model

Through Maxwell and Simplorer, the simulation models of each module are connected to each other to realize joint simulation, the system model is shown in Fig. 7. Set the stator resistance of 
$0.01 \mathrm{mOhm}$, the inductance of $0.12093 \mathrm{mH}$, the rotational inertia of $0.035 \mathrm{~kg} / \mathrm{m} 2$, inverter switch frequency of $10 \mathrm{kHz}$, the entire simulation time of $0.3 \mathrm{~s}$. The maximum step size is set to $0.5 \mathrm{us}$, the minimum step size to $1.5 \mathrm{us}$, the initial given speed of $800 \mathrm{r} / \mathrm{min}$, set the electromagnetic torque jump to $15 \mathrm{~N} . \mathrm{m}$ from $5 \mathrm{~N} . \mathrm{m}$ at $0.1 \mathrm{~s}$, rotational speed jump to $2400 \mathrm{r} / \mathrm{min}$ at the $0.2 \mathrm{~s}$, then run the simulation model to get the following waveform:

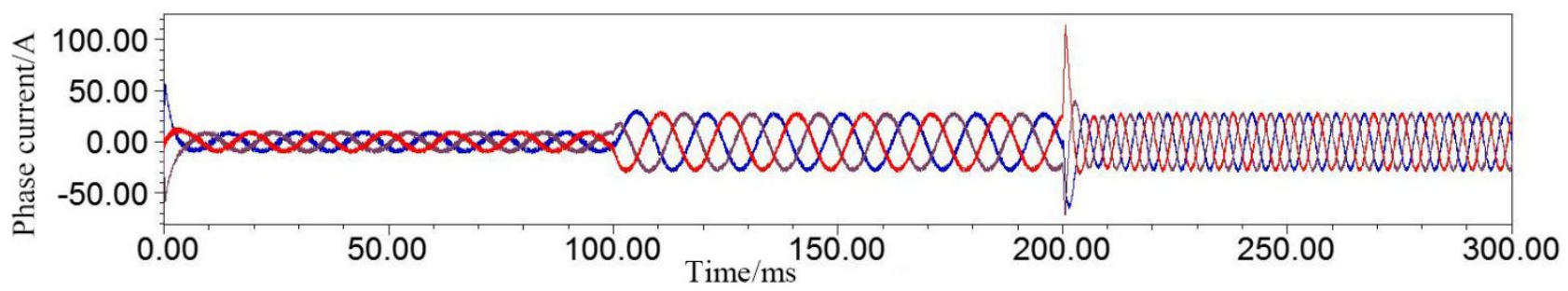

Fig. 8. $\mathrm{I}_{\mathrm{a}}, \mathrm{I}_{\mathrm{b}}, \mathrm{I}_{\mathrm{c}}$ phase current waveform
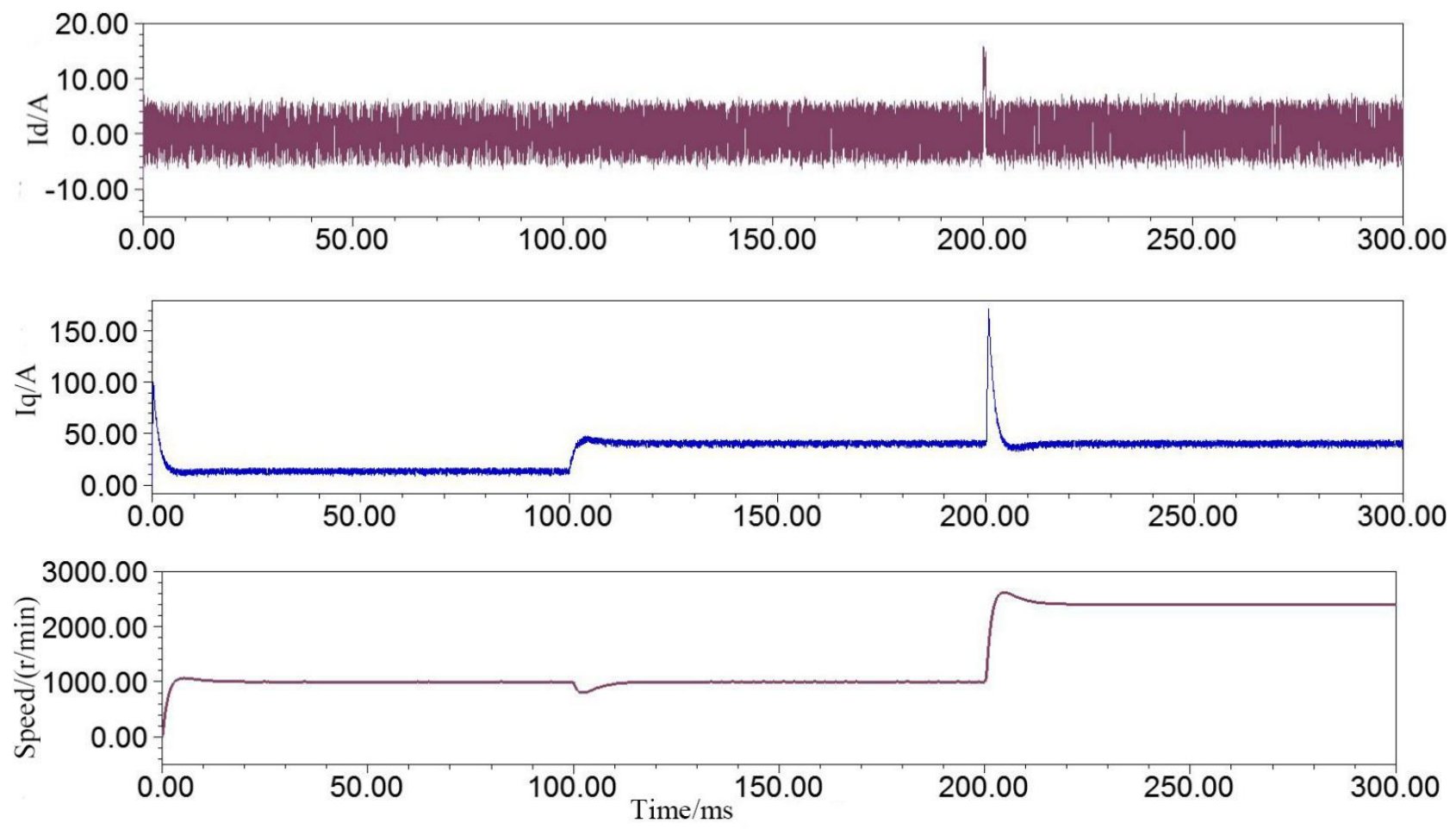

Fig. 9 Motor speed and current Iq waveform

I
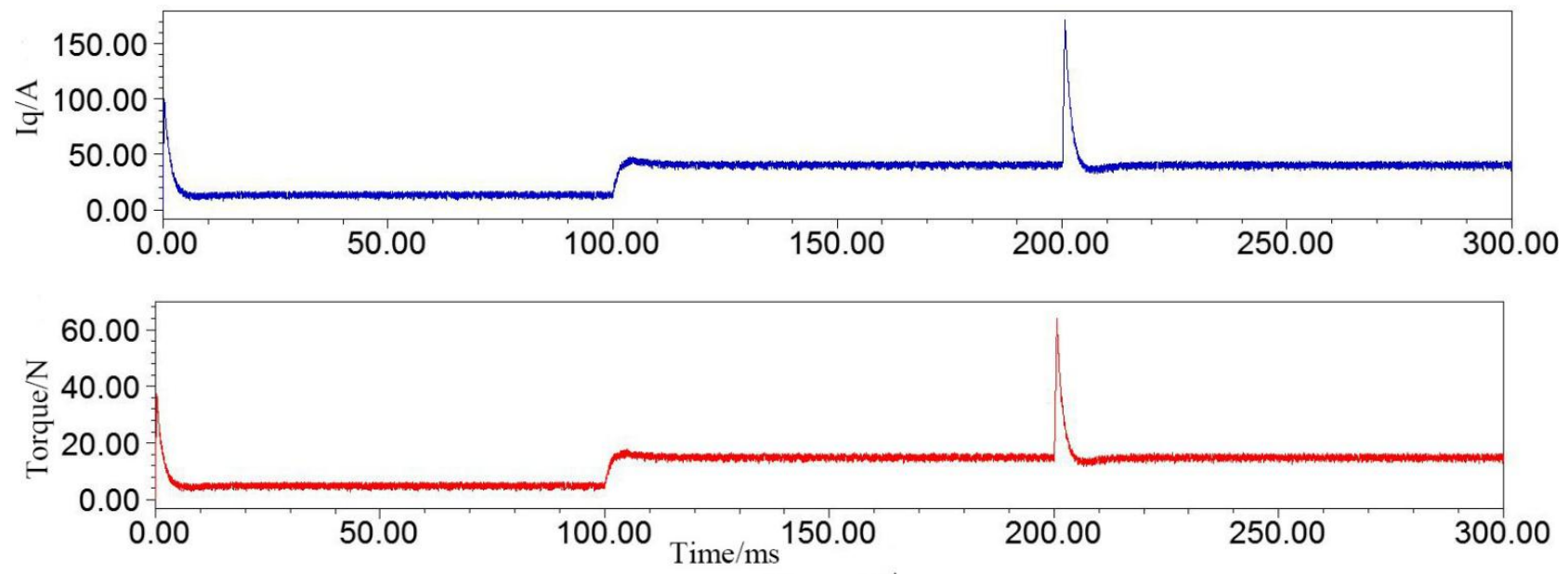

Fig. 10 Motor torque and current Iq waveform 
Through the simulation waveform, it can be seen, as shown in Fig. 9, the starting time of about $20 \mathrm{~ms}$, speed overshoot is less than $20 \mathrm{r} / \mathrm{min}$. The speed accuracy is relatively higher, between $-3 \sim 3 \mathrm{r} / \mathrm{min}$. In the case of sudden change in $0.1 \mathrm{~s}$ load, according to Fig. 10, it is found that the motor, after about $15 \mathrm{~ms}$ adjustment, can achieve stable operation, the stability of this control system is strong. The rotational speed of the stator current $\mathrm{i}_{\mathrm{abc}}$ changes from $1000 \mathrm{r} / \mathrm{min}$ to $2400 \mathrm{r} / \mathrm{min}$ at $0.2 \mathrm{~s}$, after 2-3-cycle adjustment, that is, stable to sine wave, so the system's rotational speed adjustment performance is good. According to Fig. 11, the motor torque is proportional to the iq, and the change rule is consistent, thus, the desired effect is achieved. Therefore, the simulation results of the motor control strategy are satisfactory.

\section{Conclusions}

In this paper, the structure of PMSM vector control system is analyzed, the control principle is briefly analyzed, the complete control model is constructed by using rotational speed and torque double closed loop system, and the two-dimensional model and electromagnetic analysis of permanent magnet synchronous motor are established in Maxwell Environment. The motor controllers, inverter circuits and so on are modeled and simulated by using the Simplorer as a simulation platform, and the joint simulation with Maxwell is achieved, the corresponding simulation model and results are obtained finally, the response speed of this model is fast, the system can run smoothly, which has good static and dynamic characteristics, the correctness and rationality of the whole design scheme is verified.

\section{References}

[1] Kachino S,Kiseleva V,Servoa B. Research of operation modes of the synchronous electric motor drive system with use of software ANSYS maxwell and simplorer [ J ].Micro/Nanotechnologies and Electron Devices, 2014(7) : 362-364.

[2] Kallio S, Andriollo M, Tortella A, et al. Decoupled d-q model of double-star interiorpermanent-magnet synchronous machines [J]. IEEE Transactions on In-dustrial Electronics, 2013, 60(6): 2486-2494

[3] Harnefors L, Nee H P model-based current control of AC machines using theinternal model control method [J]. IEEE Transactions on Industry Applicat1onS,1998,34(1):113-141

[4] Harnefors F, Pietilainen K, Gertmar L. torque-maximizing field-weakeningcontrol: design, analysis and parameter selection [J]. IEEE Transaction on Industrial Electronics, 2001, 48(1): 161-168

[5] Chen Zhiqian, Tomita M, Doki S, et al. An extended electromotive force modeltorsensorless control of interior permanent-magnetsynchronous motors [J]IEEE Transactions on Industrial Electronics, 2003, 50(2): 288-295

[6] Ghafari-Kashani A R, Faiz J, Yazdanpanah M J Integration of non-linear Hooand sliding mode control techniques for motion control of a permanent magnetsynchronous motor [J]. IET Electric Power Applications, 2010, 4(4): 267-280. 